\section{Equity in health care and institutional trust: a communitarian view}

\author{
Eqüidade na assistência à saúde e confiança \\ institucional: uma perspectiva comunitária
}

\author{
1 Social and Public Health \\ Economics Research Group \\ (SPHERe), Curtin University \\ Perth, Australia. \\ Correspondence \\ G. Mooney \\ Social and Public Health \\ Economics Research Group, \\ Curtin University. \\ Health Sciences, Bldg 400, \\ Curtin University, \\ Bentley Campus, \\ PO Box U1987, Perth WA \\ 6845, Australia. \\ g.mooney@curtin.edu.au
}

\begin{abstract}
Communitarianism acknowledges and values, and not just instrumentally, the bonds that unite and identify communities. Communitarians also value community per se. This paper argues that trust is likely to be stronger in communities where these bonds are greater. Equity in health care is a social phenomenon. In health care, it is apparent that more communitarian societies, such as Scandinavia and within Aboriginal Australia, are likely to value more equity-orientated systems. Where, as in the latter case, this desire for equity takes place against a background of the powerful dominant (white) society treating the minority (black) society as dependent, Aboriginal trust in Australian society and in its public institutions is eroded. Lack of trust and inequity then come to the fore. This paper discusses institutional trust as a facilitator of equity in health care in the specific context of Indigenous health. The example used is Australian Aboriginal health but the principles would apply to other Indigenous populations as in for example South America.
\end{abstract}

Equity in Health; Delivery of Health Care; Indigenous Population; Community-Institutional Relations
Gavin Mooney ${ }^{1}$

Shane Houston 1

\section{Introduction}

This paper considers two facets of trust in the context of equity in health care: institutional trust and generalized trust. The key focus is on the first. It is argued that a lack of trust in health care as a social institution can create access barriers. Where different groups of people face different barriers to use health care, services are likely to be inequitable.

Second, the greater the pervasiveness of trust in a society - what Gilson ${ }^{1}$ has referred to as "generalized trust" - the more likely the willingness of people to be concerned for others who are in some material sense different. In the context of equity in health care, this generalized trust might enhance willingness to subscribe, perhaps through a tax-based health care system, to the provision of health care of these others who are different. The less trust there is in "the other", especially if that other is different in some particularly relevant characteristic, such as health status or ethnicity, the less likely the willingness to contribute to these others' access to health care. As Uslaner $^{2}$ (p. 128) has expressed it, "When people trust each other, they are more likely to accommodate others' preferences". The paper subscribes to the importance of this form of distrust but does not deal with it in any depth.

The discussion of equity does not require any specific definition beyond noting that equity as equal access for equal need sits well with the ar- 
guments in the paper. In the next section, the relationship between communitarianism and trust is laid out. This is followed by a discussion in the section Cultural Security and Trust with specific reference to Aboriginal Australians and the problems of lack of institutional trust. That example can almost certainly be extended to other indigenous peoples and probably to other disadvantaged groups as well. The paper concludes by highlighting lack of institutional trust as a major barrier to more equal access to health care, especially where this is accompanied by generalized distrust.

\section{Communitarianism and trust}

This section lays out the possible advantages of considering trust from a communitarian stance. It first considers communitarianism, then trust, and thereafter sets trust in a communitarian setting.

The philosophy of communitarianism acknowledges and values, and not just instrumentally, the bonds that unite and identify communities. Communitarians value community per se. Where there are greater social bonds, trust is likely to be both more pervasive and stronger.

A communitarian view on equity in health care has been put forward elsewhere (with Black) by one of us ${ }^{3}$. In this, health care ceases to be an individualistic normal good but becomes a community good. What this means in practice is two things. First, at the same time as accepting, as many if not most economists do, that markets for health care fail, there is a need to replace markets as resource allocation processes rather than trying to "patch them up". This also, second, requires that whatever replaces markets needs to be based in some sense on the values of the community qua community rather than those of individuals as in the market.

The communitarian critique of liberalism and the liberal state suggests that "it is well-nigh impossible for proponents of political liberalism to handle the empirical fact that citizens achieve their identity through participating in various collectivities" 4 (p. 39).

Turning to the question of trust in the context of health care, Gilson 1 relates this phenomenon to decision-making. She quotes Rothstein (1998, apud Gilson 1; p. 1462) as arguing that " $[\mathrm{t}]$ he design given to political institutions such as health systems governs the notions of morality and justice prevailing in society".

This however might also work in the opposite direction. The morality and justice prevailing in a society are likely to govern the design given to political institutions such as health systems. It is this latter point that forms the main thrust of this paper. This is especially the case with respect to equity where morality and justice are most likely to find a home.

Uslaner 2 partially echoes Gilson when he writes of the high level of trust that exists in Norway and Sweden. That can be linked to the fact that Scandinavian countries are renowned for their "Scandinavian solidarity". It thus comes as no surprise that trust there is high.

Gilson 1 (p. 1458) states: "Public organizations build their legitimacy when they demonstrate through organizational and managerial practices values and norms that underlie or are associated with trust (...) the peculiar nature of health care (...) means that legitimacy is particularly important to health policy implementation". That legitimacy is challenged however when, as in the case of Aboriginal Australia (see below), a history of oppression and dispossession leaves Aboriginal people with a deep sense of institutional distrust in its wake. She quotes Misztal (1996, apud Gilson 1; p. 1458) who argues that "trust cannot be fully understood and studied without the examination of institutions as repositories of values and without addressing a practical issue of how far human beings' concepts of duties and obligations are influenced by the societal institutions which organize the ways in which people are bound together".

Uslaner 2 argues that where people are trusting they tend to be more tolerant and willing to accept differences in people and in turn differences in culture. Where a whole people - such as Australian Aborigines - lose faith in their future as a people, the problems for building trust can become very great indeed.

When more generally potential patients or citizens do not trust "the system", i.e. where there is a lack of trust in the institution of health care, this creates barriers to use. When further they do not trust the person or persons, such as the doctor or the nurse, who offers treatment, still other barriers arise. What is of particular concern in this paper are the institutional trust barriers, although clearly different types of trust are linked.

As an example we can take the question of the dissemination of information in health care. This can be aimed at too high an education or comprehension level, which may in turn lead to confusion or even misinformation for some. While that per se is not necessarily a matter of trust, it is easy to see how such barriers can lead potential patients to distrust not only the information but also, and more importantly in the context of this paper, the institution which has at best con- 
doned or at worst approved the dissemination of such information.

Communities where mutuality and reciprocity are more common will tend to be more attached to trust and trustworthiness. Generalized trust is more likely to prevail in a more communitarian society. It will thus be easier (and less costly) to set up trusted institutions the more a community is communitarian and the less it is individualistic. The cost of suspicion and distrust of institutions and, in many instances, in turn, of the state more generally, can be high. If that suspicion and distrust are deep seated, if they are not only individually-based but also culturallybased as in, say, one or more ethnic sub-populations in a society, then the prospects for dealing satisfactorily with such distrust are not good and potentially costly (as exemplified in the section Conclusion).

Equity in health care can readily be fitted into this context. Such equity is a social phenomenon and is more appropriately recognized and articulated as such than in the Rawls liberal and in essence individualistic interpretation ${ }^{4}$. It is also significant that trust in the form of generalized trust is absented behind the veil of ignorance. One might even argue that it is generalized distrust that drives the choice in Rawls to seek to benefit the least advantaged. This makes it all the more necessary to adopt a non-liberal interpretation of both trust and equity in health care policy.

To do so in social services such as health care however is not a simple matter. Kettl 5 has suggested for example that the natures of social and health services are such that precision in stating in advance what outcomes are wanted is difficult.

Read in the context of institutional trust, Kettl's statement highlights the need to develop a trusting relationship both to support and to "oil" questions of control and monitoring in health care. There are seldom if ever neatly packaged health service "products" which "consumers" can identify as being precisely what they seek to "buy". This is true of all patients. Many disadvantaged people however face not only poor health status but also poor access to health care and even poorer information regarding the outcomes of health care. Their distrust of the institution of health care is then potentially so much greater. This in turn contributes to greater access barriers.

While other access barriers may arise because of for example money fees at the point of consumption, yet others can occur as a result of "gaps" between providers and patients, in class, education, or ethnicity. These gaps can be inter- preted in different ways, and also bridged in various different ways. In this paper building trust is held out as being one way of performing this bridging role.

Institutional distrust is unlikely to be distributed equally across a population. It is more likely to reside in those who are disadvantaged or vulnerable in other ways, such as through poverty or ill health. There are parallels here with the conceptualization by Walzer 6 of spheres of justice. In other words, people who suffer deprivation or disadvantage are more likely to be distrustful.

In the specific context of health care, social entities that are more communitarian in nature, such as in Scandinavian society and within Aboriginal Australia, will tend to have a stronger preference for equity and in turn for more equity-orientated health care systems. Where, as in the latter case, the desire by Aboriginal people for equity takes place against a backdrop of a lengthening history of the powerful dominant (white) society treating the minority (black) society as dependent, of dispossession of land and erosion of culture, there is a breakdown in Aboriginal generalized trust in Australian society and in Aboriginal institutional trust in Australian public institutions. Interwoven with these issues are the difficulties in maintaining the more communal life world of Aboriginal culture alongside the more individualistic life world of white Australia. The conflict between the social autonomy of the former and the individualistic autonomy of the latter is an unequal one. Lack of trust and inequity then come to the fore.

This inter-cultural breakdown of trust is all too readily apparent in Australian society as is true of other societies where indigenous people are a minority. In Australia, Aboriginal people are a small proportion of the total (about 3\%). Non-Aboriginal Australia is by far the dominant culture. The history of colonization since 1788, when the British invaded Aboriginal Australia, the denial of the very existence of Aboriginal people as people until 1967, and two centuries of persecution of both Aboriginal people and their culture have done nothing to build trust. Dispossessed of their land and their rights and faced with at best paternalism and at worst persecution, dispossession and death, Aboriginal people lost their trust in the institutions of government and the organizations, such as health services, which are supposed to be there for them. Lack of respect for Aboriginal values, such values being devalued and discounted by the "do-gooders" who have sought patronizingly and paternalistically to make Aboriginal people good in terms that suit white people, leads to further erosion of trust. This occurs not only in the lack of trust 
by Aboriginal people in white people and white institutions. Perhaps more tellingly, it has led to a lack of trust by Aboriginal people in themselves as a people and in their culture. Thus one of the most debilitating aspects of this history is experienced in the impact on self-trust, not only at an individual level, but across Aboriginal peoples and their culture. The loss of trust in their own culture has perhaps caused the greatest havoc of all that has been visited upon Aboriginal people. This idea of cultural self-trust (here cultural selfdistrust) is one that we might usefully add to the trust lexicon of Gilson 1.

\section{Cultural security and trust}

In this section the paper looks more specifically at trust and the related concept of "cultural security" for Aboriginal people. This represents a special case of inequity that arises because of a combination of a loss of generalized trust and a lack of institutional trust by one particular group in a society. As Thiede 7 (p. 1456) argues more generally "the more culturally diverse a society, the more likely it is that low-trust environments are created".

Nussbaum 8 (p. 359) argues that trust "appears to require (...) generally fortunate circumstances of life (...) a repeatedly betrayed or disappointed person will be fearful and suspicious of everything". It is easy to recognize that Aboriginal people have been "repeatedly betrayed or disappointed" not just as persons, but as a people. The impact on trust is bound to be considerable.

Aboriginal people have long asserted the instrumental relevance of the recognition of culture and community to strategies for improving Aboriginal socioeconomic status and health. Participation in cultural networks and social milieu enjoined individuals and groups to the collective whole. The essence of Aboriginal society is communitarian as one of us has described 9 . The lack of attention to cultural values and rights in the development of services to Aboriginal individuals and communities has for some time stood as a practical limitation on how far it has been possible to go in establishing health services that Aboriginal people will trust, use, and rely on. This lack of cultural security in this communitarian society has proved and remains problematic for Aboriginal people and their health.

Such cultural security has been defined by one of us 10 (p. 24) as "a commitment that the construct and provision of services offered by the health system will not compromise the legitimate cultural rights, views, values, and expectations of Aboriginal people. It is a recognition, apprecia- tion, and response to the impact of cultural diversity on the utilization and provision of effective clinical care, public health, and health systems administration".

The practical implication of cultural security is that the administrative, clinical, and other service domains of the health system need to be reviewed to ensure that their operation appropriately incorporates culture at all levels and in the system as an institution. A careful analysis of pathways in health in areas that are considered important to Aboriginal people is required to establish priorities for action. This examination will reveal where change is necessary. Progress in these areas will build trust in and acceptance of health services and facilities that can then lead to health gain.

The contemporary public policy approach to improving the health system's appreciation of Aboriginal cultural needs in Australia is cultural appropriateness/awareness. The foundation of this approach is a commitment to "train" staff about Aboriginal culture. The intention of the process is to influence the attitude and awareness of individual staff in the hope or anticipation that their subsequent behavior may change. Cultural awareness tends to be generic and is seen by Aboriginal people as a soft option, leading many to conclude that it has not delivered trust in an adequate manner to overcome the alienation and discomfort they face in seeking to use health services. They remain not worthy of their trust.

This policy of cultural awareness does not have a systems or institutional focus. The target is the individual worker. Insofar as current policy in Australia with respect to Aboriginal health care does embrace trust, it is with respect to trying to build individual trust. It does not address institutional trust.

Cultural security is focused directly on practice, skills, and behaviors; it is about effectiveness. It is about building the competence of practitioners and administrators to know, understand, and incorporate Aboriginal cultural values in the design, delivery, and evaluation of health services. Such cultural security makes institutions such as health services essentially social institutions and helps to maintain and foster the communitarianism of Aboriginal society. It is about trust, seeking both to achieve the trustworthiness of institutions as part of civic society and to have Aboriginal people, as a people, to be trusting of health care as a social institution, as a part of their community.

This marriage of trustworthiness with trusting is the essence of cultural security. It involves a deepening of the health system's commitment to ensuring respect for and practical incorpora- 
tion of cultural values in the practice of delivering health services.

It is concluded that trust, in this form of cultural security in Aboriginal Australia, if not a prerequisite for equity in health care, has at least the capability to be a major facilitator.

Aboriginal people believe that if Aboriginal culture were to be given greater recognition and the values of society were brought into play in the health debate, trust but also cooperation and the notion of shared responsibility for members of the community inherent in culture, in essence reciprocity, would contribute to an improvement in the health and well-being of individuals and families.

The extent to which individuals are able to have confidence in the social interaction between members of the community and are able to trust the values and other underpinnings of these interactions and to understand the relationships this creates e.g. reciprocity 11 has an impact on the physical and mental health of the members. Where Aboriginal people represent the dominant population and are able to influence the civic and cultural life of the community, their health and well-being are strengthened 12 . Where Aboriginal people are in a minority, are less able to make regular contact with members of their own social network, and do not trust the underpinnings of the social structure around them, they are more likely to suffer from doubts of self-worth and ability to engage. Under such circumstances the mental and physical health of individuals and of families may suffer 11 .

Studies 13 have shown that "civic communities" value solidarity, civic participation, and integrity. Such entities are those areas where members become engaged in the public life of the community not because of "what's in it for me" but because they recognize the generalized benefit to all members of collective action on various important public issues. The roots of civic communities are well grounded in the shared historical cultural, economic, and social experience of the people. This experience brings with it an acceptance of reciprocity between members and implied and generalized trust 1 .

Unfortunately it remains the case that there is institutional racism in Australian health services 14. There are many examples. One emerges from a study looking at the use of Medicare (the Australian public health insurance system) by Aboriginal and non-Aboriginal people 15. For those born in the 1940s, Aboriginal people over a three-year period in the mid-1990s got just over \$1,000 (Australian) of benefits while non-Aboriginal people received nearly $\$ 1,800$. The level of benefits of $A b$ original people hospitalized was only $67 \%$ of that for non-Aboriginal people. Yet Aboriginal people are on average much sicker when they enter hospital. In effect Aboriginal people were receiving nursing care while non-Aboriginal people were obtaining high-cost medical interventions.

It is such institutional behavior that results in a lack of trust by Aboriginal people in Australian health services as a social institution. It is clear that for Aboriginal people, access to health care is more difficult, not just because of racism per se but because the cultural barriers are higher than for non-Aboriginal people. This access element is primarily a function of lack of cultural security.

Cultural security in this context is closely aligned with trust, although it is not synonymous with it. While Aboriginal health policy is replete with stories of why Aboriginal health is so poor today, to date the extent to which lack of institutional trust in the form of cultural security has been recognized as a major barrier to a more equitable health care system is limited.

\section{Conclusion}

This paper has sought to discuss the idea that placing trust, especially institutional trust, in a communitarian context can provide useful insights into equity in health care, especially across different cultures. Where societies or social entities have a greater concern for mutuality, reciprocity, and sharing and also have a more optimistic view of their future, trust in institutions is likely to be fostered and equity in health care will be a more likely outcome for that society.

Taking this perspective, the paper argues that in Australian Aboriginal health the lack of institutional trust is perhaps the biggest barrier to the promotion of better health for Aboriginal people. Until services are made culturally secure, which means in essence building institutional trust, such barriers will remain. It is not costless in resource terms; not to deal with it is not costless in health terms. The health and access to health care of indigenous peoples more generally, for example in South America, and of other disadvantaged groups might benefit from being analyzed in similar terms of institutional trust. 


\section{Resumo}

O comunitarismo reconhece e valoriza (e não apenas no sentido instrumental) os elos que unem as comunidades e com os quais se identificam. Além disso, os comunitaristas também valorizam a comunidade em si. O artigo propõe que a confiança tende a ser maior naquelas comunidades onde os elos são mais sólidos. A eqüidade na assistência à saúde é um fenômeno social. Nos cuidados de saúde, fica evidente que sociedades mais comunitárias, tais como na Escandinávia ou entre os povos aborígines da Austrália, tendem a valorizar sistemas mais orientados para a eqüidade. No caso dos aborígines, o desejo de eqüidade aparece contra o pano de fundo de uma sociedade dominante poderosa (branca) que trata a minoria (negra) como dependente, levando à erosão da confiança dos aborígines na sociedade e nas instituições públicas australianas. Nesse contexto predominam a desconfiança e a falta de eqüidade. $O$ artigo discute a confiança institucional como facilitador da eqüidade na assistência à saúde no contexto específico da saúde indígena. $O$ exemplo utilizado é a saúde dos aborígines australianos, mas os princípios se aplicam a outras populações indígenas, como as da América do Sul.

Equidade em Saúde; Assistência à Saúde; População Indígena; Relações Comunidade-Instituição

\section{Contributors}

The two authors contributed equally to the ideas in this paper and the writing of it.

\section{References}

1. Gilson L. Trust and the development of health care as a social institution. Soc Sci Med 2003; 56: 1453-68.

2. Uslaner EM. Democracy and social capital. In:Warren M, editor. Democracy and Trust. Cambridge: Cambridge University Press; 1999. p. 121-50.

3. Black M, Mooney G. Equity in health care from a communitarian standpoint. Health Care Anal 2002; 10:193-208.

4. Rawls J. A theory of justice. Cambridge: The Belknap Press of Harvard University; 1971

5. Kettl D. Sharing power: public governance and private markets. Washington DC: The Brookings Institution; 1993.

6. Walzer M. Spheres of justice. Oxford: Blackwell; 1983.

7. Thiede M. Information and access to health care: is there a role for trust? Soc Sci Med 2005; 61: 1452-62.

8. Nussbaum M. The fragility of goodness. Cambridge: Cambridge University Press; 1986.

9. Houston S. The past, the present, the future of Aboriginal health policy [Doctoral Dissertation]. Perth: Curtin University; 2004.
10. Houston S. Aboriginal cultural security. Perth: Health Department of Western Australia; 2001.

11. Stansfeld S. Social support and social cohesion. In: Marmot M, Wilkinson R, editors. Social determinants of health. Oxford: Oxford University Press; 1999. p. 155-78.

12. Cornell S. The importance of power of indigenous self-governance: evidence from the United States. Indigenous Governance Conference, April 2002. http://fp.arizona.edu/soc/Cornell_cv_fall_06.pdf (accessed on 09/Oct/2006).

13. Putnam R. Making Democracy Work. Princeton: Princeton University Press; 1993.

14. Henry B, Houston S, Mooney G. Institutional racism in Australian health care. A plea for decency. Med J Aust 2004; 180:517-20.

15. McGuire T, Houston S, Rohwedder E, Montague G. Identifying Aboriginal person care in hospital and Medicare documentation. Perth: Health Department of Western Australia; 1998.

Submitted on $20 /$ Oct $/ 2006$ Approved on 13/Mar/2007 